\title{
Emotional Intelligence and Risk Leadership on the Effectiveness of ISO 31000 Implementation in Organisation
}

\author{
Aldi Ardilo \\ CyberWhale, Indonesia
}

\begin{abstract}
ISO 31000 indicates that risk management is a science in which competencies are embedded in the individuals. It also emphasises the importance of having proper leadership while demonstrating the commitment towards the risk management implementation. Humans are emotional creatures-we could sometimes be influenced by the force of feelings, rather than rational discussion. This paper describes the dynamics of emotional intelligence and risk leadership in implementing risk management. The research used a qualitative-descriptive design with the verification strategy of case study. It used a non-probability sampling to individuals in the top management position. The findings suggest that without a proper level of emotional intelligence, it is difficult for leaders to cultivate an effective risk culture. These findings may equip decision makers on the interrelationships between emotional intelligence, risk culture, and organisation's risk management maturity.
\end{abstract}

Keywords: Risk Management, Risk Leadership, Emotional Intelligence

This is an open access article under the CC-BY-NC license.

\section{INTRODUCTION}

Awareness has risen for the importance of managing risks to thrive in this capricious and rapidlychanging business environment-not to mention the effects of COVID-19 pandemic. International Organisation for Standardisation (ISO) has established an international standard of risk management guideline, ISO 31000, which the latest version was published in 2018. Interestingly, in the 16-page standard, it predominantly emphasises on the importance of leadership in order to effectively implement risk management in an organisation.

In practice, risk often produces a negative reaction in individuals which ultimately ends in avoidance. It depends on many factors, one of which is the culture of the organisation (Barnabei, 2008). Notwithstanding personal beliefs that might affect one's psychological processes, organisational culture is one of the most familiar, and most influencing concepts as it would affect all of the organisational members on an everyday basis. Moreover, Lehman et al. (2004) suggests that psychological processes influence culture and, fascinatingly, culture influences psychological processes as well. Individual thoughts and actions influence cultural norms, practices, and behaviours as they evolve over time, and these sets of behaviours influence the thoughts and actions of individuals or a larger entity, such as organisations.

Specifically, in managing risks, an organisation should have a mature risk culture which is the critical foundation for implementing risk management best practices (Barnabei, 2008). The collective attitudes within organisations contribute to the overall risk culture-likewise, people shape the risk culture of an organisation, and so does the risk culture influence how people respond and react towards organisational risks. However, there has been little examination on this soft competency of risk management, lots of research focused on the hard competencies instead. Therefore, this study emphasises on risk leadership while taking account the culture and attitudes involved which are highly influenced by emotions (Salovey et al., 2004). Correspondingly, a leader's reaction and action will be depending on the perception of emotions in a particular situation (Apter, 1992). Hence, the importance of having the ability to perceive and literate emotions for leaders to demonstrate their risk leadership.

Risk is not an exact matter and is multi-interpretative in nature. In addition, having the capacity to control emotion is important as well as the ability to demonstrate leadership in an organisation (Ochsner and 
Gross, 2005). This research, thence, would also be taking the capability of leaders regarding emotional intelligence into the equation. Particularly, this research focuses on the dynamics of emotional intelligence in regards to the way a person demonstrates their risk leadership which, ultimately, affects the risk management maturity of an organisation. Therefore, the aim of this study is to address the question of how emotional intelligence and risk leadership affect the effectiveness of a risk management implementation based on ISO 31000 in an organisation.

\section{LITERATURE REVIEW} Risk Management

ISO 31000:2018 defines risk management as coordinated activities to direct and control and organisation with regard to risk, and it provides a set of guidelines intended to streamline risk management for organisations through an architecture consist of three main components, namely (1) Principles; (2) Framework; and (3) Process.

At the centre of its principles, risk management has a purpose of value creation and protection. These 8 principles are the basis on which organisation should implement and carry out risk management practices: (1) Integrated; (2) Structured and comprehensive; (3) Customised; (4) Inclusive; (5) Dynamic; (6) Best available information; (7) Human and cultural factors; and (8) Continual development.

Risk management principles have to be embedded in every risk management activity; while risk management framework is an organisation-based setting. According to ISO 31000:2018, risk management framework is a set of components that provide the foundations for implementing risk management throughout the organisation. In practice, one of the main outputs of is a policy that defines the roles, responsibilities and accountabilities of risk management throughout an enterprise.

While the risk management framework is applicable for a single organisation, the risk management process has to be executed on every single risk identified (Susilo \& Kaho, 2018). Risk management process is basically the core of its implementation; and it could be simplified into three main stages: (1) Establishing scope, context, and criteria; (2) Risk assessment includes risk identification, analysis, and evaluation; and (3) Risk treatment. It is also equipped with three supporting stages that should be embedded on each of the main stages mentioned: (1) Communication and consultation; (2) Monitoring and review; and (3) Recording and reporting.

\section{RISK LEADERSHIP}

In an organisational context, a leader is someone responsible to implement organisational agendas into a realisation through the results of certain activities (Lee et al., 2011). In terms of risk management, a risk leader is someone that comprehend the principles, framework, process and its implementation in the organisation.

Leadership, on the other hand, has two intertwined approaches-physiological and psychological aspects. Physiological aspect emphasises on something concrete and rational; whereas psychological aspect tends to direct a trait to an emotional dimension. Leadership is a trait on how a person could become a role model through which objectives can be achieved (Crosby, 1997). ISO 31000:2018 explicitly states that top management, both board of directors or executive board and board of commissioners or non-executive board, must articulate and demonstrate risk leadership in their organisation and be committed to their own leadership as well as any policies regarding risk management initiatives and activities. An effective risk leadership would form an effective risk culture since without the right culture in place, any efforts on risk management would remain a formality (Hillson \& Murray, 2007). Hillson (2002) stated that what makes risk management culture crucial is because it has a critical influence on the effectiveness of risk management. Risk culture is attached to an individual mind, which then influences his or her behaviour and actions in terms of risk management.

Risk leader, leadership and culture are interconnected concepts that make one attribute which describe how risk management perceived and interpreted by the people of an organisation, affect their behaviours and course of actions at implementing risk management (IRM, 2012). 


\section{RISK MANAGEMENT MATURITY}

Top management should understand and evaluate its organisation's capabilities and capacities of risk management, and what should be done upon it. Risk management maturity is a helping tool for management to build their risk management capabilities and capacities (Alijoyo, 2019).

In 2020, Enterprise Risk Management Academy (ERMA) developed a risk management maturity model known as ERMA RM ${ }^{3}$. ERMA RM ${ }^{3}$ was constructed based on ISO 31000:2018 and is expected to provide a balanced view of managing opportunities and risks while capturing dynamic elements that affect the organisation's sustainable growth. There are six attributes to be measured: (1) Risk management framework; (2) Risk management process; (3) Process management; (4) Performance management; (5) Risk management culture; and (6) Resilience and sustainability. Table 1 indicates the Criteria of ERMA $\mathrm{RM}^{3}$.

Table. 1 ERMA RM ${ }^{3}$ Risk Management Maturity Model

\begin{tabular}{cccl}
\hline $\begin{array}{c}\text { RISK } \\
\text { MATURITY }\end{array}$ & RANGE & CRITERIA & \multicolumn{1}{c}{ INTERPRETATION } \\
\hline Initial & $0-20 \%$ & 1 & $\begin{array}{l}\text { Risk management is still an ad-hoc, relies on individual } \\
\text { initiative }\end{array}$ \\
\hline Repeatable & $21 \%-40 \%$ & 2 & $\begin{array}{l}\text { Risk management starts to be systematically } \\
\text { implemented }\end{array}$ \\
\hline Defined & $41 \%-60 \%$ & 3 & $\begin{array}{l}\text { Risk management has been implemented } \\
\text { systematically and consistently practiced as per ISO } \\
31000\end{array}$ \\
\hline Optimised & $80 \%-100 \%$ & 5 & $\begin{array}{l}\text { Risk management has been integrated with } \\
\text { organisational governance and management } \\
\text { systematically and consistently practiced as per ISO } \\
\text { 31000 }\end{array}$ \\
\hline
\end{tabular}

\section{Emotional Intelligence (EI)}

In most cases, leaders manage their organisational risks without significant efforts and concerns with regard to comprehend, express, and manage emotion in doing so. Bar-On (2013) defines emotional intelligence (EI) as "an array of interrelated emotional and social competencies, skills and behaviours that determine how well we understand and express ourselves, understand others and relate with them, and cope with daily demands, challenges, and pressures. In short, EI is an ability to percept, understand, manage, and utilise emotions to facilitate thinking processes (Mayer \& Salovey, 1997, in Bar-On, 2006). Bar-On elaborates further that EI consists of 5 emotional dimensions along with 15 sub-dimensions (see Table 2). A person with a high level of EI is able to manage changes in inner self, social and environment with realistic and flexible coping in case new situations come. In line with that, Goleman (2000) pointed out that EI forms an imperative part of leadership and decision-making effectiveness as it highly correlates with one's behaviour in an organisation. 
RSF Conference Series: Business, Management and Social Sciences, Vol. 1 (5), 11-20

Emotional Intelligence and Risk Leadership on the Effectiveness of ISO 31000 Implementation in Organisation Aldi Ardilo

Table. 2 Emotional Intelligence Dimensions (Bar-On, 2006)

EI SCALES

INTRAPERSONAL

Self-regards

Emotional self-awareness

Assertiveness

Independence

Self-actualisation

INTERPERSONAL

Empathy

Social responsibility

Interpersonal relationship

STRESS MANAGEMENT

Stress tolerance

Impulse control

\begin{tabular}{ll}
\hline ADAPTABILITY & Change management \\
\hline Reality-testing & To objectively validate one's feelings and thinking with external reality \\
\hline Flexibility & To adapt and adjust one's feelings and thinking to new situations \\
\hline Problem-solving & To effectively solve problems of a personal and interpersonal nature \\
\hline GENERAL MOOD & Self-motivation \\
\hline Optimism & To be positive and look at the brighter side of life \\
\hline Happiness & To feel content with oneself, others and life in general \\
\hline
\end{tabular}

\section{EI COMPETENCIES AND SKILLS ASSESSED}

Self-awareness and self-expression

To accurately perceive, understand and accept oneself

To be aware of and understand one's emotions

To be aware of and constructively express one 'emotions and oneself

To be self-reliant and free of emotional dependency on others

To strive to achieve personal goals and actualise one's potential

Social awareness and interpersonal relationship

To be aware of and understand how others feel

To identify with one's social group and cooperate with others

To establish mutually satisfying relationships and relate well with others

Emotional management and regulation

To effectively and constructively manage emotions

To effectively and constructively control emotions

Change management

\section{RESEARCH GAP}

Every organisation, basically, has done risk management activities to some certain extent, whether intentionally or not; holistically or partially; and integrated or siloed (CRMS, 2019). Renn (1998) and Grote (2011) emphasise that the application of risk management is one of the fastest growing business fields, and it has become an important agenda in various sectors and industries across the globe. In particular in Indonesia, the government has taken risk management onto the national-level agenda. In fact, the Financial Services Authority (OJK) has issued regulations related to risk management implementation not for banking industry only; however, The Indonesian Financial Services Authority Regulation (POJK) No. 44 of 2020 clearly states that the non-bank financial institutions, including insurance, pension funds and financing companies are obliged to set up a risk committee and to carry out effective enterprise risk management. Besides, the government has also included risk management to the Medium-Term National Development Plan (RPJMN) 2020-2024. Additionally, the Ministry of StateOwned Enterprises has officially declared that as of 2021 every listed Indonesian state-owned enterprise is compulsory to have a risk management unit and board-level executive who is in charge of the implementation of enterprise risk management.

The urgency of implementing risk management has been accentuated within the country; therefore, many organisations require their human resources to be competent in risk management. As a result, many knowledge-intensive business services, such as training companies, professional certification bodies, universities, etc., provide and facilitate risk-management-related upgrading programs. The most 
provided subjects for risk management are about the fundamentals-principles, framework, and process-risk assessment techniques, risk-based internal audit, project risk management; and the implementation of risk management based on the relevant regulations for certain companies. In an interview session with one of the leading risk management training providers in Indonesia-Center for Risk Management and Sustainability (CRMS) Indonesia-from the total training activities, as of 2021, there were around 28 public programs and some request-upon in-house programs. All of the programs were designated to address the technical and hard competencies of risk management. Moreover, all requests for in-house training are also related to the technical of risk management implementation. On the contrary, even though risk leader and risk leadership are recognised as the key factors for success in implementing risk management, they were the least studied. In a much bigger scope, the number of research regarding the psychological process of a person in demonstrating his or her risk leadership in implementing risk management are relatively small—and thus, the interrelations are not well elaborated. To address this gap, this study takes the emotional intelligence as the psychological process of one's risk leadership into the big equation of risk management implementation in an organisational context.

\section{RESEARCH METHOD}

\section{Research Approach}

This paper is an exploratory study in which the best appropriate method to obtain answers for its research questions is by using qualitative research approach (Kothari, 2004). The methods used to analyse data and generate new findings in this qualitative research is by conducting case studies.

\section{Methodology}

Risk management is not an exact matter and is multi-interpretative in nature; therefore, different perception brings out a different emotion, different course of action, different risk culture and also different attitudes toward the risk. An open-ended response will be necessary to address these multiinterpretative issues as it also requires validated data-collection instruments to put the dimensions of emotional intelligence into account. To analyse the data and generate new findings, the author will use case studies as its main verification strategy. The research uses both direct and indirect approaches for collecting all of the empirical evidence necessary, namely, self-administered questionnaire, semistructured individual interview, direct and indirect observation, and secondary data.

The Bar-on (2006) emotional intelligence questionnaire will be adopted and adjusted to Indonesian language and organisational context. The author ran a validity test through evidence based on test content using expert judgement by, at least, three experts in the field of risk management, governance, as well as industrial and organisational psychology. Afterwards, a try out session was carried out to 30 samples through which internal consistency will be assessed. Moreover, correlation test was executed through an item discrimination analysis. Should an item score be below 0.3 , it will be revised, and the entire adopted questionnaire will redo the validity and reliability test until all items in the questionnaire are greater than 0.3. The questionnaire then is distributed through both online and on site to eight risk management practitioners.

The proxy used to indicate an organisation's risk management implementation effectiveness is risk management maturity. It will be assessed based on ERMA RM ${ }^{3}$ that uses both primary and secondary data gathering. The author will observe the implementation of risk management processes according to ISO 31000 in informants' organisations. In terms of risk management maturity, there are six attributes that will be assessed in every stage of the existing risk management processes. Primary data will be gathered through semi-structured interview sessions with the relevant stakeholders involved in the execution of the risk management process and the dynamics of risk leadership within the organisation. Whereas secondary data will provide proofs or evidence which support the interview results.

The author used a purposive sampling to collect data of eight informants' level of EI through a questionnaire, semi-structured interview, and observation. Furthermore, based on ISO 31000:2018 and ERMA RM ${ }^{3}$, the author provides a hypothetical-based description of the dynamic of informants' leadership in the attempt of managing organisational risks within a firm which result was used as a basis to construct interview questions and context for direct observation. Afterwards, through another interview risk leadership and maturity level were assessed based on their activities in implementing the principles, framework and processes of risk management. Specifically for primary data, the study mainly used a 
narrative analysis that took into account the context of each informant's case and different experiences of each informant in his or her particular organisational context.

\section{Sample Characteristics}

The setting of this research was in Indonesia since the government has accentuated the urgencies on risk management implementation as it has been established to be one of the agenda of the Medium-Term National Development Plan (RPJMN) 2020-2024. Moreover, in practice, risk management is a board-level agenda and based on Hofstede's cultural dimensions theory, in a high-context culture-including Indonesia-strategic decision such as risk management is argued to be a top-down process; hence, the significant role a leader has. For those reasons, the criteria for the informants of this research are risk management practitioners that have been working as board-level executives for at least 2 years in an Indonesian organisation that was not compulsory to implement risk management by regulation; though they were encouraged to do so.

\section{FINDINGS AND DISCUSSION}

\section{Results}

Eight informants, who come from different organisations, were interviewed based on the questionnaire of EI (see Table 3). Afterwards another set of questions were asked to investigate the organisation's risk management maturity which are supported by secondary data as proof or evidence. Table 4 summaries the EI's dimensions of each informant towards the risk management maturity of the organisation in which they operate. Whereas Table 5 describes the detailed scores for the risk management maturity assessment in each of their organisations along with each informant's-as the organisation's leaderemotional intelligence category.

Table 3 Overall Informants' EI and Risk Management Maturity

\begin{tabular}{ccccc}
\hline Informant & $\begin{array}{c}\text { Emotional } \\
\text { Intelligence }\end{array}$ & $\begin{array}{c}\text { Risk Management } \\
\text { Maturity }\end{array}$ & Industry & Organisation Size ${ }^{[\mathbf{1}}$ \\
\hline A & Low & Initial & Education & Micro \\
\hline B & Low & Repeatable & Construction & Small \\
\hline C & Moderate & Initial & Accommodation & Small \\
\hline D & Moderate & Initial & Retail & Small \\
\hline E & Moderate & Repeatable & Education & Micro \\
\hline F & Moderate & Defined & $\begin{array}{c}\text { Information and } \\
\text { communication }\end{array}$ & Micro \\
\hline G & High & Defined & Education & Small \\
\hline H & High & Managed & Manufacturing & Small \\
\hline
\end{tabular}

${ }^{[1]}$ In assets; in IDR, properties are excluded. Micro: <500 Billion; and Small: 500 Billion - 1 Trillion

Table 3 depicts the overall emotional intelligence profile of the eight informants. Based on five dimensions of EI, the author classified the informants into three different categories of EI: low, moderate, and high. There are two informants with low EI and high EI; while the other four are in the moderate category. The risk management maturity of each informant's organisation is somewhat distributed, especially for the low and moderate EI category. The two informants with high EI were operating at their organisation with a relatively higher maturity level with regard to risk management implementation. In addition, the recapitulation on Table 3 also displays the background of each informant in order to better understand each of their organisational contexts which then relate to each of their risk management implementation cases 
Table. 4 EI Dimensions Toward Risk Management Maturity

\begin{tabular}{cccccccc}
\hline $\begin{array}{c}\text { Informa } \\
\text { nt }\end{array}$ & $\begin{array}{c}\text { Emotion } \\
\text { al } \\
\text { Intellige } \\
\text { nce }\end{array}$ & $\begin{array}{c}\text { Intraperso } \\
\text { nal }\end{array}$ & $\begin{array}{c}\text { Interperso } \\
\text { nal }\end{array}$ & $\begin{array}{c}\text { Stress } \\
\text { Managem } \\
\text { ent }\end{array}$ & $\begin{array}{c}\text { Adaptabil } \\
\text { ity }\end{array}$ & $\begin{array}{c}\text { Genera } \\
\text { I Mood }\end{array}$ & $\begin{array}{c}\text { Risk } \\
\text { ent } \\
\text { Maturity }\end{array}$ \\
\hline A & Low & Low & Low & Low & Low & Low & Initial \\
\hline B & Low & Low & Low & Low & Moderate & Low & Repeatable \\
\hline C & Moderate & Moderate & Low & Moderate & Moderate & Low & Initial \\
\hline D & Moderate & Moderate & Moderate & Low & Moderate & $\begin{array}{c}\text { Modera } \\
\text { te }\end{array}$ & Initial \\
\hline E & Moderate & Moderate & Moderate & Moderate & Moderate & $\begin{array}{c}\text { Modera } \\
\text { te }\end{array}$ & Repeatable \\
\hline F & Moderate & Moderate & Moderate & High & Moderate & $\begin{array}{c}\text { Modera } \\
\text { te }\end{array}$ & Defined \\
\hline G & High & Moderate & High & High & Moderate & High & Defined \\
\hline H & High & Moderate & High & High & High & High & Managed \\
\hline
\end{tabular}

Bar-On (2002) states that in elaborating emotional intelligence, a mere, generic score will be inadequate, and therefore it requires a deep understanding of every profile of its components (or dimensions). Table 4 describes the recapitulation of the five dimensions of EI towards each of the informant's organisation's risk management maturity level. Table 4 sorts the informants from the lowest score of EI, including its five dimensions, to the highest. Only two informants (A and E) who have a consistent trend of EI on every dimension. Informants in the moderate EI category tend to have a more varied profile compared to other informants in the low and high category. There are two informants who are in the moderate category but operate in organisations with an initial stage of risk management maturity. Nonetheless, informant $F$ with a moderate EI but high on stress management dimension operates in an organisation with a defined level of risk management maturity. 
RSF Conference Series: Business, Management and Social Sciences, Vol. 1 (5), 11-20

Emotional Intelligence and Risk Leadership on the Effectiveness of ISO 31000 Implementation in Organisation Aldi Ardilo

Table. 5 Attributes of Risk Management Maturity Toward EI

\begin{tabular}{|c|c|c|c|c|c|c|c|c|}
\hline \multirow{2}{*}{$\begin{array}{c}\text { ATTRIBUTE } \\
\mathbf{S} \\
\end{array}$} & \multicolumn{8}{|c|}{ INFORMANT / ORGANISATION } \\
\hline & A & B & C & D & $\mathbf{E}$ & $\mathbf{F}$ & G & $\mathbf{H}$ \\
\hline $\begin{array}{c}\text { Risk } \\
\text { Culture }\end{array}$ & 0.83 & 1.25 & 0.67 & 0.67 & 2.17 & 3.00 & 3.00 & 2.75 \\
\hline $\begin{array}{c}\text { Risk } \\
\text { Managemen } \\
\text { t } \\
\text { Framework } \\
\end{array}$ & 0.17 & 1.46 & 0.29 & 0.29 & 1.92 & 2.46 & 2.29 & 3.46 \\
\hline $\begin{array}{c}\text { Risk } \\
\text { Managemen } \\
\text { t Process }\end{array}$ & 0.75 & 1.63 & 0.75 & 0.75 & 1.75 & 3.25 & 2.88 & 3.38 \\
\hline $\begin{array}{c}\text { Managemen } \\
\text { t Process }\end{array}$ & 1.75 & 2.38 & 1.75 & 1.125 & 2.625 & 4.00 & 3.75 & 4.5 \\
\hline $\begin{array}{c}\text { Performanc } \\
\text { e } \\
\begin{array}{c}\text { Managemen } \\
t\end{array}\end{array}$ & 1.00 & 1.33 & 1.00 & 1.00 & 2.00 & 3.00 & 2.50 & 3.42 \\
\hline $\begin{array}{l}\text { Resilience } \\
\text { And } \\
\text { Sustainabili } \\
\text { ty }\end{array}$ & 1.00 & 1.58 & 1.50 & 1.33 & 1.38 & 2.13 & 1.58 & 2.54 \\
\hline Aggregated & $\begin{array}{c}\text { Initia } \\
1\end{array}$ & $\begin{array}{c}\text { Repeatab } \\
\text { le }\end{array}$ & Initial & Initial & $\begin{array}{c}\text { Repeatab } \\
\text { le }\end{array}$ & Defined & $\begin{array}{c}\text { Define } \\
\text { d }\end{array}$ & $\begin{array}{c}\text { Manage } \\
\text { d }\end{array}$ \\
\hline $\begin{array}{c}\text { Maturity } \\
\text { Level }\end{array}$ & $\begin{array}{c}18.3 \\
\%\end{array}$ & $33.1 \%$ & $19.9 \%$ & $17.2 \%$ & $39.4 \%$ & $59.4 \%$ & $53.3 \%$ & $66.8 \%$ \\
\hline $\begin{array}{l}\text { Emotional } \\
\text { Intelligence } \\
\text { (EI) }\end{array}$ & Low & Low & $\begin{array}{c}\text { Moderat } \\
\mathrm{e}\end{array}$ & $\begin{array}{l}\text { Moderat } \\
\mathrm{e}\end{array}$ & Moderate & $\begin{array}{c}\text { Moderat } \\
\text { e }\end{array}$ & High & High \\
\hline
\end{tabular}

Table 5 recapitulates the attributes of risk management maturity in the risk management implementation in each of the informants' organisations and their EI category. Data were gathered and analysed based on the implementation of risk management (1) principles or in creating and protecting value; (2) framework or in demonstrating leadership and commitment; and (3) process or communicating, consulting, establishing the context, and identifying, analysing, evaluating, treating, monitoring and reviewing organisational risks. Most of the cases, the organisations tend to have a higher score in documents compared to other factors. Documents refer to internal policies, regulations or any other rules related to risk management implementation in the organisation as well as reports and documentations. The organisation of informants with high EI tend to have a more effective risk management implementation compared to others in moderate and low category, in particular for risk management process attributes. Likewise, the attitudes toward risk management implementation in each component of risk management are higher under the leadership of informants with higher EI.

\section{Dynamics of Risk Leadership and Emotional Intelligence}

Risk leaders in the low category of EI are relatively difficult to accurately perceive and literate emotionsin both themselves and others. Though they believe that risk management is one of the keys factors for success in sustainability growth, particularly during or after the COVID-19 pandemic, other people in their organisations seemingly failed to understand the urgencies to implement risk management. Informant A explained, "other employees take any risk management efforts as an additional job and a disturbance to the current work conditions - even the tiny initiatives." Similar situation was also exhibited in informant B's organisation in which the leader believes that the majority of employees do not approach risk management initiatives in a proactive fashion; rather, they were reluctant. Informant B had attempted to do regular audits; however, instead of being compliant and keen to improve, most employees were demotivated. The awareness of risk management and an effective risk culture simply did not exist in both organisations. Some employees were also interviewed, and the vast majority of both organisations 
claimed that there was no common ground on why an organisation should do risk management; in other words, the rationale and justifications were not established and well-communicated. Informant $\mathrm{A}$ asserted that she did not completely understand the reasoning of risk management herself, and therefore she was solely telling everybody what to do based on what ISO 31000 guidelines suggest. While informant B explicitly said that he just did not realise that other employees did not understand since he believed that though it has many limitations, the rationale had already been established even before the pandemic occurred. Bar-On (2013) elaborates that EI can be improved, and the ability to understand and to express inner self (intrapersonal) is the foundation to develop other abilities. Leaders with low EI may not be able to accurately perceive emotions, making it more difficult to understand what others' need. This most definitely inhibited them to have a harmonious relationship with others-in this case, employees.

Leaders in the moderate category have a more varied profile of risk leadership compared to other categories. Nevertheless, these leaders may display an inconsistent set of behaviour in the overall risk management implementation. Informant $C$ supported this idea as he stated that sometimes he is a calm risk leader, and sometimes he is being rather impulsive. Likewise in informant D's organisation, the leader argued that he cannot really get everybody to be on the same page, specifically in terms of risk culture cultivation-"everything seems to be siloed, though I have tried to listen to what they want and needs", informant D explained. Informants $\mathrm{E}$ dan $\mathrm{F}$ have done quite well in cultivating risk culture as the employees' attitudes throughout the risk management processes are shaping to an appropriate one. In organisation $\mathrm{F}$, this condition was supported by the fact that there were some risk awareness digital campaigns sent periodically to employees' devices. On top of that, some employees emphasised that they were actually looking up to informant $\mathrm{F}$ in implementing risk management in their everyday job. He also tends to be assertive and helpful when a subordinate makes a mistake or is not confident in doing some risk-related tasks.

The two leaders with high EI have articulated their leadership by establishing a number of official documents as the realisation of commitment to implement risk management in their organisations. Employees in informant H's organisation implied that he has a leadership style that makes him consistently adjust his own approaches to the personality and the situation of other employees. To the high achievers, he managed to further encourage them by giving difficult-yet-attainable challenges; whereas to those who resist from changes, he gave an understanding that could ultimately unfreeze the old mindset. "He leads by giving examples, and he is not just a supervisor, but also a mentor and a friend", another board member commented. Risk management significantly depends on people's capability and capacity. Based on that, change management has to be effectively led in order to cultivate an effective risk culture-hence, a good-tailored risk leadership. In case of informant G, though the organisation was at the defined level, the leader was viewed as a person that could not necessarily see a helicopter view of a problem in which an impulsive behaviour sometimes emerged. This phenomenon is somewhat in line with her slightly lower adaptability, compared to other dimensions. On the other hand, she managed to demonstrate a risk leadership with a high-degree of empathy within the process. With a high general mood, she indirectly spread the spirit to her subordinates upon which a relatively appropriate risk culture was cultivated.

The Risk Management Association and Protiviti (2014) elucidates that risk culture is the glue that binds all elements of risk management infrastructure together. One of the key roles for a risk leader in an organisation is to lead the change that refers to the effect of transformations, amendments, alterations, or modifications made in implementing or improving risk management practices. The nature of the topdown process heightens leaders' roles since they are key people to actually determine whether an organisation could effectively carry a risk management out. Accordingly, these key people have to influence and bring the opinion of other emotional beings. Thus, the importance of the ability to perceive and literate emotions to lead the change in order to cultivate an effective risk culture through appropriate risk leadership. As a result, a higher risk management maturity level could be achieved as the appropriate culture can be thickened as it is iterated in everyday practices.

\section{CONCLUSION}

The focus of this paper was how risk leaders' EI affect the effectiveness of risk management implementation in an organisation. The author looked over the aspects of EI for their influences on risk leadership and ultimately on risk management maturity. These influences should drive an organisation 
to remove any potential barriers and build an effective culture that is mature in risk awareness. The findings suggest that leadership could lead an organisation to a successful risk management or to a failure. Roles of leaders are further stressed in high-context cultures as the aspects are supporting the nature of a top-down process even more. Specific to Indonesian context, a risk leadership plays a crucial and determining part in achieving a matured risk management practice. Leaders must demonstrate and exhibit a strong risk leadership through - since it is the matter of affecting other humans-a high degree of emotional literacy and capability; hence, EI comes into play. As Bar-On stated, EI could be enhanced and improved. The one thing a leader should pay attention to is the intrapersonal dimension as it is the foundation of all of the others ability to accurately perceive emotions through which a leader could drive the existing and emerging changes that could bring rightful risk leadership to cultivate effective risk culture, and ultimately a matured risk management practices. Additionally, due to its limitations, further research is required to explore broader samples and other settings in a low-context culture; also, the interrelationship of other soft-competencies in implementing risk management can be further investigated.

\section{REFERENCES}

Alijoyo, A. (2019). Risk Maturity - Mengapa diperlukan? Indonesian Risk Management Professional Association (IRMAPA), accessible at https://irmapa.org/maturitas-risiko-risk-maturity-mengapa-diperlukan/.

Apter, M. J. (1992). The Dangerous Edge. New York: Free Press.

Barnabei, Mark D. (2008). Risk Management Psychology and Practice. Master of Science in Organizational Dynamics Theses, 24, http://repository.upenn.edu/od_theses_msod/24

Bar-On, R. (2002). The Emotional Quotient Inventory (EQ-i): Technical Manual. Toronto, Canada: Multi Health System, Inc.

Bar-On, R. (2006). The Bar-On Model of Emotional-Social Intelligence (ESI). Psicothema, 18, supl., 13-25.

Bar-On, R. (2013). A Broad Definition of Emotional-Social Intelligence According to the Bar-On Model, accessible at https://reuvenbaron.org.

Center for Risk Management and Sustainability (CRMS) Indonesia. (2019). Sustaining through GRC. Governance Risk Management Compliance National Survey 2019, pp. 1.

Crosby, P. B. (1997). The Absolutes of Leadership. San Francisco: Jossey-bass, pp. 2.

ERMA. (2020). ERMA Risk Management Maturity Model ISO $31000 \mathrm{RM}^{3}$. Methodology and Application of ISO 31000-Based Risk Management Maturity Assessment, https://erm-academy.org.

Goleman, D. (2000). Leadership that gets results. Harvard business review, 78(2), 4-17.

Grote, Gudela. (2011), "Risk management from an organizational psychology perspective: A decision process for managing uncertainties", Die Unternehmung. 65. 10.5771/0042-059X-2011-1-69.

Hillson, David. (2002). Extending the risk process to manage opportunities. International Journal of Project Management. 20. 235-240. 10.1016/S0263-7863(01)00074-6.

Hillson, D.A. \& Murray-Webster, R. (2007). Understanding and Managing Risk Attitude. Burlington, Vt.: Grower Publihsing Co.

Institute of Risk Management (IRM). (2012). Risk culture: Resources for Practitioners. The institute of Risk Management, pp. 22-27.

ISO. (2018). ISO 31000:2018 Risk Management Guidelines. International Organization for Standardization, Geneva, Switzerland.

Kothari, C. (2004). Research Methology: Methods and Techniques: $2^{\text {nd }}$ edition. Delhi: New Age International (P) Ltd.

Lee, Peter \& Cheng, T. C. E. \& Yeung, Andy \& Lai, Kee-hung. (2011). An empirical study of transformational leadership, team performance and service quality in retail banks. Omega. 39. 690-701. 10.1016/j.omega.2011.02.001.

Lehman, Darrin \& Chiu, Chi Yue \& Schaller, Mark. (2004). Psychology and Culture. Annual review of psychology. 55. 689-714. 10.1146/annurev.psych.55.090902.141927.

Ochsner, K. \& Gross, J. J. (2005). The Cognitive Control of Emotion. Trends in Cognitive Science, 9, pp. 242-249.

Renn, O. (2008). "Risk Governance - Coping with uncertainty in a complex world", London.

Risk Management Association and Protiviti. (2014). Risk Culture: From Theory to Evolving Practice. The RMA Journal December 2013-January 2014.

Salovey P., Brackett M. A. \& Mayer J. D. (2004). Emotional Intelligence: Key Readings on the Mayer and Salovey Model. Port Chester, NY, US: National Professional Resources Inc.

Susilo, L. \& Kaho, V. R. (2018). Manajemen Risiko ISO 31000:2018 - Panduan untuk Risk Leaders dan Risk Practitioners. Jakarta: Kompas Gramedia. ISBN: 978-602-05-1234-1. 